\title{
Occurrence of teichuronopeptide in cell walls of group 2 alkaliphilic Bacillus spp.
}

\author{
Rikizo Aono,* Masahiro Ito and KoKi Horikoshi \\ Department of Bioengineering, Faculty of Bioscience and Biotechnology, Tokyo Institute of Technology, \\ Nagatsuta 4259, Midori-ku, Yokohama 227, Japan
}

(Received 22 March 1993; revised 11 June 1993; accepted 1 July 1993)

\begin{abstract}
Cell walls were prepared from four strains belonging to group 2 alkaliphilic Bacillus spp. Non-peptidoglycan components were extracted, with trichloroacetic acid, from the cell wall preparations and isolated by DEAEcellulose column chromatography. All the components were acidic, and were composed of amino acids and sugars. Several components with different compositions were detected. The cell walls commonly contained teichuronopeptide, composed of polyglucuronic acid and a polypeptide of acidic amino acids.
\end{abstract}

\section{Introduction}

Gram-positive bacteria possess cell walls composed of peptidoglycan and other specific polymers, such as proteins and polysaccharides. The cell walls of several alkaliphilic strains of the genus Bacillus also have specific polymers. These strains have been divided into three groups on the basis of the chemical composition of their walls and other physiological characteristics (Aono \& Horikoshi, 1983). The walls of group 2 organisms contain large amounts of acidic amino acids and uronic acids. Although most strains in group 2 can grow at a neutral $\mathrm{pH}$, the same acidic amino acids and uronic acids are found in much smaller quantities in the cell wall preparations when the bacteria are grown in this way. This indicates that the acidic components in the outermost cell layer of the group 2 bacteria might have a function in supporting growth at an alkaline $\mathrm{pH}$.

The structural components of the cell wall of the alkaliphilic Bacillus strain C-125 have already been described. It contains Al $\gamma$-peptidoglycan, teichuronic acid and teichuronopeptide (Aono et al., 1984; Aono, 1985, 1989). The teichuronic acid is composed of galacturonic acid, glucuronic acid and $\mathrm{N}$-acetylfucosamine (Aono \& Uramoto, 1986); the teichuronopeptide is a complex of polyglutamic acid and polyglucuronic acid. Similar components are suspected to be present in other group 2 alkaliphilic Bacillus strains, as large

*Author for correspondence. Tel. +81459221111 ; fax +8145923 0377.

Abbreviation: TFMS, trifluoromethanesulphonic acid. amounts of uronic acids and acidic amino acids have been found in their cell walls (Aono, 1987). However, no structural analysis of the cell walls of these bacteria has been reported.

This paper describes the isolation and partial characterization of the acidic structural components of the cell wall of group 2 alkaliphilic Bacillus strains.

\section{Methods}

Cultivation of organisms and preparation of cell walls. The alkaliphilic strains of Bacillus spp. used in this study, A-59, C-3, C-11 and Y-25 (Aono \& Horikoshi, 1983), were grown aerobically at $30^{\circ} \mathrm{C}$ in $6-18$ litres of the following medium: ( $\mathrm{g}$ per litre of deionized water): $\mathrm{K}_{2} \mathrm{HPO}_{4}, 13.7 ; \mathrm{KH}_{2} \mathrm{PO}_{4}, 5.9$; citric acid, $0.34 ; \mathrm{MgSO}_{4} .7 \mathrm{H}_{2} \mathrm{O}, 0.05$; $\mathrm{Na}_{2} \mathrm{CO}_{3}, 10 \cdot 6$; glucose, 5 ; peptone, 5 ; yeast extract, $0 \cdot 5$. The $\mathrm{pH}$ of this medium was about 10 . Cells in the early stationary phase of growth $\left(\mathrm{OD}_{660} 2 \cdot 0\right)$ were harvested by centrifugation $\left(8000 \mathrm{~g}, 10 \mathrm{~min}, 4^{\circ} \mathrm{C}\right)$. The cells were resuspended in $2 \%(\mathrm{w} / \mathrm{v}) \mathrm{SDS} / 0.1 \mathrm{M}-\mathrm{NaCl}$ and incubated at $80^{\circ} \mathrm{C}$ for $30 \mathrm{~min}$ to inactivate autolytic enzymes. The cells were recovered by centrifugation $\left(8000 \mathrm{~g}, 20 \mathrm{~min}, 20^{\circ} \mathrm{C}\right)$, washed with $0 \cdot 1 \mathrm{M}-\mathrm{NaCl} / 0 \cdot 1 \% \mathrm{NaN}_{3}$ and stored at $-20^{\circ} \mathrm{C}$.

Cell walls were prepared from the frozen cells as described previously (Aono \& Horikoshi, 1983).

Isolation of the non-peptidoglycan components. Each cell wall preparation (2-3 g dry wt) was suspended in $200 \mathrm{ml} 5 \%(\mathrm{w} / \mathrm{v})$ trichloroacetic acid (TCA). The suspension was gently shaken at $30^{\circ} \mathrm{C}$ for 10-12 h. Non-peptidoglycan components, solubilized with TCA, were recovered in the supernatant fluid obtained after centrifugation $\left(20000 \mathrm{~g}, 20 \mathrm{~min}, 4^{\circ} \mathrm{C}\right)$. The insoluble fraction of the cell wall preparation was extracted twice more with TCA. The extracts were then combined and thoroughly dialysed against running water (Spectra/Por 6 dialysis tubing, $M_{\mathrm{r}}$ cut-off 3500; Spectrum Medical Industries).

After the dialysis, a solution containing the non-diffusible material was diluted twofold with $100 \mathrm{~mm}$-acetic acid/ $\mathrm{NaOH}$ buffer (pH 5.0). The solution was loaded on a DE-52 DEAE-cellulose column 
$(2.5 \times 50 \mathrm{~cm}$; Whatman) which had been equilibrated with $50 \mathrm{~mm}$ acetic acid/ $\mathrm{NaOH}$ buffer (pH 5.0). The column was washed with $500 \mathrm{ml}$ of the buffer at a flow rate of $120 \mathrm{ml} \mathrm{h}^{-1}$. The column was eluted, at the same rate, with $250 \mathrm{ml}$ of the buffer containing $0.2 \mathrm{M}-$ $\mathrm{NaCl}$, followed by a linear gradient elution from 0.2 to $0.6 \mathrm{M}-\mathrm{NaCl}$ in the buffer $(700 \mathrm{ml})$ at a flow rate of $60 \mathrm{ml} \mathrm{h}^{-1}$. Fractions $(15 \mathrm{ml})$ containing uronic acids and amino compounds were pooled, dialysed against deionized water and concentrated in a rotary evaporator at $43^{\circ} \mathrm{C}$.

The acidic polymers fractionated by DEAE-cellulose column chromatography, were applied on a column $(2.5 \times 100 \mathrm{~cm})$ of Fractogel HW-55S (separation range $M_{\mathrm{r}} 1000-200000$ for dextran; Merck) or 65S ( $M_{\mathrm{r}}$ 10000-1000000 for dextran; Merck) which had been equilibrated with $0.2 \mathrm{M}-\mathrm{NaCl}$. The column was eluted with $0.2 \mathrm{M}-\mathrm{NaCl}$ at a flow rate of $30 \mathrm{ml} \mathrm{h}^{-1}$. Fractions $(8.5 \mathrm{ml})$ containing uronic acids and amino compounds were pooled, dialysed against water and freezedried (Aono, 1985).

Trifluoromethanesulphonic acid (TFMS) treatment of the teichuronopeptides. The acidic polymer preparation ( $1 \mathrm{mg}$ dry wt) was placed in a glass tube and dried in vacuo over solid $\mathrm{NaOH}$ at $43^{\circ} \mathrm{C}$. Methoxybenzene $(0.1 \mathrm{ml})$ and cold TFMS $(0.2 \mathrm{ml})$ (Wako Pure Chemical) were added to the dried sample (Edge et al., 1981). Nitrogen gas was substituted for air in the vessel by flushing. The reaction mixture was gently shaken at $26^{\circ} \mathrm{C}$ for $4.5 \mathrm{~h}$ and frozen overnight at $-20^{\circ} \mathrm{C}$, after addition of $6 \mathrm{ml} 10 \%(\mathrm{v} / \mathrm{v}) n$-hexane in diethyl ether. The precipitate that appeared during the freezing process was recovered by centrifugation $(2500 \mathrm{~g}, 10 \mathrm{~min}$, room temperature), washed with $n$-hexane/ diethyl ether $(1: 10, v / v)$ three times and given a final wash with diethyl ether. The precipitate was dried in air and dissolved in $0.2 \mathrm{M}$ $\mathrm{NaH}_{2} \mathrm{PO}_{4} / \mathrm{NaOH}$ buffer $(\mathrm{pH} 7 \cdot 2)$. The solution was then dialysed $\left(M_{\mathrm{r}}\right.$ cut-off 3500) against distilled water (Aono, 1987).

Hydrazinolysis of the teichuronopeptides. The sample (1 mg dry wt) was suspended in $0.4 \mathrm{ml}$ anhydrous hydrazine (Takara Shuzo Co.) and heated at $100{ }^{\circ} \mathrm{C}$ for $3 \mathrm{~h}$. After removal of the hydrazine by evaporation in vacuo over concentrated $\mathrm{H}_{2} \mathrm{SO}_{4}$ (Takasaki et al., 1982), the residue was dissolved in $0.2 \mathrm{ml} 50 \mathrm{~mm}$-acetic acid/ $\mathrm{NaOH}$ buffer ( $\mathrm{pH} \mathrm{5.0)}$. The solution $(70 \mu \mathrm{l})$ was loaded on a column $(1.5 \times 85 \mathrm{~cm})$ of Sephadex G15 equilibrated with the same buffer. The column was eluted with the same buffer, at a flow rate of $20 \mathrm{ml} \mathrm{h}^{-1}$, and fractions $(1 \mathrm{ml})$ were collected. Void elution volume fractions (total $3 \mathrm{ml}$ ) were combined and retained (Aono, 1989).

Analyses. (i) Amino acids and amino sugars. Samples were hydrolysed in $4 \mathrm{M}-\mathrm{HCl}$ in sealed tubes at $100{ }^{\circ} \mathrm{C}$ for $16 \mathrm{~h}$. Amino compounds were determined by the ninhydrin method (Spies, 1957) with glutamic acid as a reference. Amino sugars were determined by the Elson-Morgan reaction with glucosamine as a reference (Spiro, 1966; Wheat, 1966). Where necessary, amino compounds were analysed with an amino acid analyser. L-Glutamic acid in the hydrolysate was determined with Lglutamate dehydrogenase (EC 1.4.1.3) and diaphorase (Beutler \& Michal, 1974). L-Aspartic acid was determined with aspartate aminotransferase (EC 2.6.1 .10) (Möllering, 1985). The D-isomer content of the acidic amino acids was estimated by subtraction of the L-form acid content from the total content of glutamic acid or aspartic acid determined with the amino acid analyser. L-Alanine was determined with L-alanine dehydrogenase (EC 1.4.1.1) (Williamson, 1985); DAlanine was determined with D-amino acid oxidase (EC 1.4.3.3) (Grassl \& Supp, 1985). All the enzymes for the assays were purchased from Boehringer Mannheim.

(ii) Uronic acids and neutral sugars. Uronic acids were determined by the carbazole reagent method with glucuronic acid as a reference (Davidson, 1966; Spiro, 1966). Glucuronic acid was estimated with the thioglycolic acid/mannose/sulphuric acid reagent (Dische, 1947). Glucose was determined by the anthrone reagent method (Spiro, 1966). (iii) Sodium ions. Sodium ions were determined with an atomic absorption spectrometer.

(iv) Dry weight. Dry weights of samples were measured by heating to constant weight at $43^{\circ} \mathrm{C}$ in vacuo over $\mathrm{NaOH}$.

(v) $M_{r}$ values. $M_{\mathrm{r}}$ values were estimated for the samples by HPLC gel filtration on columns of Shodex WS802.5F (Showa Denko) (Aono, 1987). The column was eluted with $0 \cdot 1 \mathrm{M}-\mathrm{NaH}_{2} \mathrm{PO}_{4} / \mathrm{NaOH}$ buffer (pH 7.2) at a flow rate of $1.0 \mathrm{ml} \mathrm{min}-1$. The elution pattern was monitored by measuring the differential refractive index. Pullulans (Shodex P-82; Showa Denko) were used as $M_{\mathrm{r}}$ standards to calibrate the system (Aono, 1987).

Thin-layer chromatography (TLC). Ascending Avicel cellulose thinlayer chromatograms were run in the following solvents: (A) ethyl acetate/pyridine/water/acetic acid $(5: 5: 3: 1$, by vol.) at room temperature; (B) phenol $/ 1 \%$ aqueous ammonia water $(5: 2$, by vol.) at $43^{\circ} \mathrm{C}$. For the separation of amino acid isomers, samples were developed on a CHIR plate (Merck) in solvent (C) acetonitrile/ methanol/water ( $4: 1: 1$, by vol.), together with authentic isomers, at room temperature. The compounds were located with an alkaline silver nitrate (Trevelyan et al., 1950) or ninhydrin (Stepka, 1957) spray.

Paper electrophoresis. Samples were spotted in the middle of a strip of Whatman no. 1 filter paper, $30 \mathrm{~cm}$ in length, and electrophoresed in $10 \%(\mathrm{v} / \mathrm{v})$ acetic acid/pyridine buffer $(\mathrm{pH} 2.5)$ at $12.5 \mathrm{~V} \mathrm{~cm}^{-1}$ for $2 \mathrm{~h}$ (Aono, 1985). The compounds were located as described above.

\section{Results}

\section{Preparation of cell walls and extraction of acidic polymers}

During the stationary phase of growth, the $\mathrm{pH}$ of the cultures decreased rapidly. The cells were harvested at the early stationary phase of growth to avoid exposure to the lowered $\mathrm{pH}$. When the cells were harvested, the $\mathrm{pH}$ of the cultures was $9 \cdot 1-9 \cdot 5$ (results not shown). Therefore, the cell walls described below should be representative of the alkaliphilic bacteria grown at alkaline $\mathrm{pH}$.

Cell wall fractions were prepared from SDS-treated cells of four strains, A-59 (80 g wet wt), C-3 (78 g), C-11 $(45 \mathrm{~g})$ and $\mathrm{Y}-25(58 \mathrm{~g})$, and were found to contain 820 , 510,620 and $1240 \mu \mathrm{mol}$ of uronic acids, respectively. TCA extraction solubilized $89-99 \%$ of the uronic acid residues originally found in each cell wall preparation. Most of the uronic acid was retained during thorough dialysis. Therefore, it appeared that these residues were present as constituents of some high- $M_{\mathrm{r}}$ polymers bound to peptidoglycan through acid-labile linkages.

\section{Fractionation of non-peptidoglycan components}

The non-diffusible materials obtained from the cell walls of strains C-3 and Y-25 were separated into two fractions by DEAE-cellulose column chromatography (Fig. 1b,d). One fraction (C-3-1 or Y-25-1) eluted from the column at $0.3-0.4 \mathrm{M}-\mathrm{NaCl}$ and the other $(\mathrm{C}-3-2$ or $\mathrm{Y}-25-2)$ at $0.4-0.5 \mathrm{M}-\mathrm{NaCl}$. All four fractions contained uronic acids and amino compounds as major components. The TCA extracts from strains A-59 and C- 11 each yielded a single 

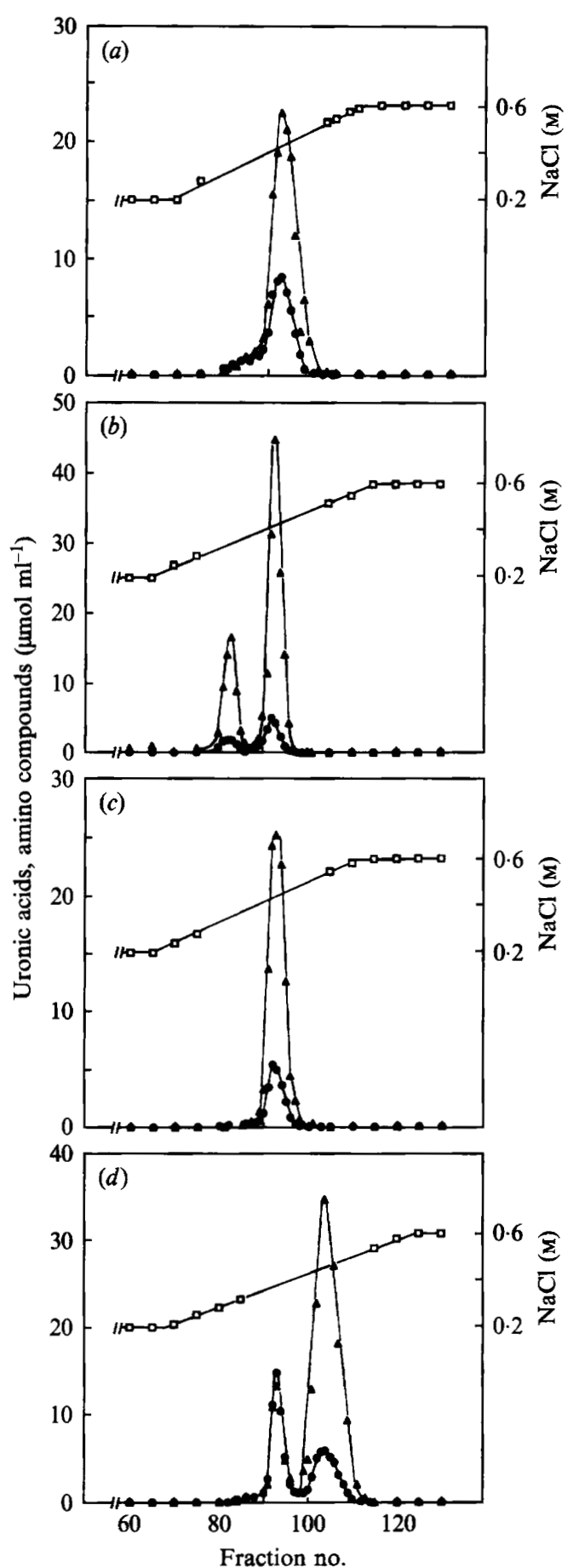

Fig. 1. Elution profile of DEAE-cellulose chromatography of the nondialysable materials of TCA extracts from strains $(a) \mathrm{A}-59,(b) \mathrm{C}-3,(c)$ $\mathrm{C}-11$ and $(d) \mathrm{Y}-25$. Chromatography was carried out as described in Methods. Fractions $(15 \mathrm{ml})$ were assayed for uronic acids $(\Theta)$, amino compounds $(\boldsymbol{\Delta})$ and $\mathrm{NaCl}(\square)$. The concentration of $\mathrm{NaCl}$ was determined from the refractive index of the fractions.

peak, again composed of uronic acids and amino compounds (Fig. 1 $a, c$ ). These two fractions eluted at $0.4-0.5 \mathrm{M}-\mathrm{NaCl}$ from the column, and were designated A-59 and C-11.
These six fractions were further purified by gel chromatography. Each fraction yielded a single overlapping peak of uronic acids and amino compounds (results not shown). Thus, these six acidic polymers appeared to be almost purified by the DEAE-cellulose chromatography. The acidic polymer obtained by dialysis and lyophilization from each fraction was designated substance A-59, C-3-1, C-3-2, C-11, Y-25-1 or Y25-2 respectively.

\section{Chemical composition of the acidic polymers}

The six substances obtained by ion-exchange and gelfiltration chromatography were hydrolysed with $\mathrm{HCl}$ under various conditions. The hydrolysates from $5 \mu \mathrm{g}$ of each substance were subjected to cellulose TLC mainly in solvent (A). Alkaline silver nitrate revealed several spots of $R_{F} 0.65$ (1), 0.35 (2), 0.32 (3), 0.12 (4) and 0.11 (5), as shown in Table 1. Spots 1 and 4 were obtained from all the samples except Y-25-1. Spots 2 and 5 were obtained only from Y-25-1. Spot 3 was produced only by C-3-1. Spot 2 also reacted with ninhydrin. Ninhydrin spray revealed further spots of $R_{F} 0.12(6), 0.08(7), 0.07$ (8), 0.06 (9) and $0.03(10)$. Spots 6 and 7 were obtained only from $\mathrm{C}-3-1$. Spot 8 occurred in all the hydrolysates except C-3-1. Spot 9 was obtained only from C-3-2. Spot 10 was produced by A-59, C-3-1 and C-3-2. Some fainter spots revealed by each spray were considered to be oligomers of the compounds.

The reducing compounds $1,3,4$ and 5 corresponded to authentic glucuronolactone, glucose, glucuronic acid and galacturonic acid, respectively. These identifications were confirmed by cellulose TLC in solvent (B) and by paper electrophoresis. The ninhydrin-positive compounds, 6,7 , 8,9 and 10 , corresponded to alanine, serine, glutamic acid, glycine and aspartic acid. These identifications were also confirmed by paper electrophoresis and with the automatic amino acid analyser. Small amounts of serine and glycine were detected in A-59 and a small amount of serine was detected in Y-25-2 with the analyser. Compound 2 did not correspond to any commercially available authentic compounds on the basis of $R_{F}$ values. This compound was thought to be an amino sugar because of its reducing ability and ninhydrin reactivity. This amino sugar was purified from the hydrolysate of a large amount of C-3-1, and identified as D-quinovosamine (Ito et al., 1993).

Isomers of alanine, aspartic acid and glutamic acid were determined enzymically. Aspartate aminotransferase did not react on the aspartic acid from any substance under conditions which permitted the enzyme to react with authentic $\mathrm{L}$-aspartic acid (Möllering, 1985). Therefore, the aspartic acid was present in the D-form. Alanine found in C-3-1 was oxidized by L-alanine 
Table 1. Composition of acidic non-peptidoglycan components purified by DEAE-cellulose and gel chromatography

The experimental details are described in Methods. Abbreviations: Ala, alanine; Asp, aspartic acid; Glu, glutamic acid; Gly, glycine; Ser, serine; Glc, glucose; GalN, galactosamine; FucN, fucosamine; QuiN, quinovosamine; GalU, galacturonic acid; GlcU, glucuronic acid. The number indicated under these abbreviations is the spot number of the respective compound detected by cellulose TLC and designated tentatively in this paper. A blank indicates not detected. Data on teichuronic acid (TUA) and teichuronopeptide (TUP) of C-125 are from Aono (1985).

\begin{tabular}{|c|c|c|c|c|c|c|c|c|c|c|c|c|c|c|}
\hline \multirow[b]{2}{*}{$\begin{array}{l}\text { Acidic } \\
\text { polymer }\end{array}$} & \multicolumn{13}{|c|}{ Component $\left[\mu \mathrm{mol}(\mathrm{mg} \text { polymer })^{-1}\right]$} & \multirow[b]{2}{*}{$M_{\mathrm{r}}^{*}$} \\
\hline & $\begin{array}{c}\text { D-Asp } \\
10\end{array}$ & $\begin{array}{c}\text { L-Glu } \\
8\end{array}$ & $\begin{array}{c}\text { D-Glu } \\
8\end{array}$ & $\begin{array}{c}\text { Gly } \\
9\end{array}$ & $\begin{array}{c}\text { L-Ala } \\
6\end{array}$ & $\begin{array}{c}\text { L-Ser } \\
7\end{array}$ & $\begin{array}{c}\text { Glc } \\
3\end{array}$ & GalN & FucN & $\underset{2}{\text { QuiN }}$ & $\begin{array}{c}\text { GlcU } \\
1,4\end{array}$ & $\underset{5}{\text { GalU }}$ & $\mathrm{Na}$ & \\
\hline $\begin{array}{l}\text { A-59 } \\
\text { C-3-1 }\end{array}$ & $\begin{array}{l}1.46 \\
0.92\end{array}$ & 1.75 & $1 \cdot 45$ & 0.07 & 0.79 & $\begin{array}{l}0.09 \\
0.35\end{array}$ & $1 \cdot 17$ & $\begin{array}{l}0.20 \\
0.02\end{array}$ & & & $\begin{array}{l}0.88 \\
0.55\end{array}$ & & $\begin{array}{l}3 \cdot 1 \\
3 \cdot 4\end{array}$ & 21000 \\
\hline C-3-2 & $1 \cdot 45$ & $1 \cdot 48$ & 1.44 & 1.39 & & & & 0.09 & & & 0.81 & & $4 \cdot 7$ & 21000 \\
\hline C-11 & & $2 \cdot 16$ & $2 \cdot 31$ & & & & & $0 \cdot 10$ & & & 0.95 & & $2 \cdot 1$ & 20000 \\
\hline Y-25-1 & & 0.96 & & & & & & 0.02 & & 1.08 & & $2 \cdot 17$ & $2 \cdot 8$ & \\
\hline$Y-25-2$ & & $2 \cdot 29$ & $2 \cdot 31$ & & & 0.05 & & $0 \cdot 10$ & & & $0 \cdot 87$ & & $2 \cdot 5$ & 21000 \\
\hline C-125 TUA & & 0.004 & & & & & & 0.04 & 1.3 & & 1.6 & $1 \cdot 5$ & $2 \cdot 8$ & 21000 \\
\hline
\end{tabular}

${ }^{*} M_{\mathrm{r}}$ estimated for each acidic polymer by gel chromatography.

Table 2. Recoveries of components of macromolecules obtained by the deglycosylation with TFMS

The teichuronopeptides $(1 \mathrm{mg})$ were treated with TFMS at $26^{\circ} \mathrm{C}$ for $4.5 \mathrm{~h}$. The deglycosylated products were washed with $10 \%(\mathrm{v} / \mathrm{v}) n$-hexane/diethyl ether and then dialysed against distilled water. The non-diffusible polypeptides were assayed for the constituents found in the original acidic polymers. Each determination is presented as $\mu \mathrm{mol}$, with percentage recovery given in parentheses. The recovery was calculated taking the content in the original untreated polymer as $100 \%$. See Table 1 for abbreviations. A blank indicates not detected.

\begin{tabular}{|c|c|c|c|c|c|}
\hline \multirow[b]{2}{*}{ Acidic polymer } & \multicolumn{4}{|c|}{ Recovery $[\mu \mathrm{mol}(\%)]$} & \multirow[b]{2}{*}{$M_{\mathrm{r}}^{*}$} \\
\hline & Asp & Glu & Gly & GlcU & \\
\hline $\begin{array}{l}\text { A-59 } \\
\text { C-3-2 } \\
\text { C-11 } \\
\text { Y-25-2 }\end{array}$ & $\begin{array}{l}0.87(60) \\
0.83(57)\end{array}$ & $\begin{array}{l}2.0(63) \\
1.7(58) \\
3.0(67) \\
3.3(72)\end{array}$ & $0.76(55)$ & $\begin{array}{l}0.015(2) \\
0.042(5) \\
0.024(3) \\
0.026(3)\end{array}$ & $\begin{array}{l}13000 \\
15000 \\
12000 \\
12000\end{array}$ \\
\hline Polyglutamate $\dagger$ & & $6.1 \mu \mathrm{mol}$ & & $0.015 \mu \mathrm{mol}$ & 14000 \\
\hline
\end{tabular}

${ }^{*} M_{\mathrm{r}}$ value of the polypeptide preparation.

$\dagger$ For polyglutamate, the results shown are $\mu \mathrm{mol}$ of each constituent per $1 \mathrm{mg}$ of the product from the C-125 teichuronopeptide deglycosylated at $0^{\circ} \mathrm{C}$ for $5 \mathrm{~h}$, then at $22^{\circ} \mathrm{C}$ for $2 \mathrm{~h}$ (Aono, 1987).

dehydrogenase but not by $\mathrm{D}$-amino acid oxidase, indicating that the alanine was in the L-form (Grassl \& Supp, 1985; Williamson, 1985). With the exception of C-3-1 and Y-25-1, the samples contained almost equimolar Dand L-glutamic acid. The serine found in C-3-1 was examined by chelating chromatography on the CHIR plate. The $R_{F}$ value of the serine derived from C-3-1 $(0.45)$ corresponded to authentic L-serine $\left(R_{F} 0.46\right)$ but not to D-serine $\left(R_{F} 0.42\right)$ in solvent $(\mathrm{C})$.

These identifications for constituents of the acidic components are summarized in Table 1 . The analyses accounted for a considerable part of the dry weight of each preparation, as follows: A-59, 87\%; C-3-1, 59\%; C-3-2, $93 \%$; C-11, 85\%; Y-25-1, $73 \%$; Y-25-2, $84 \%$. It is probable that most of the components were identified and determined, except in the case of C-3-1 and Y-25-1.

\section{Identification of teichuronopeptide among the acidic polymers}

The above analyses did not indicate the chemical nature of the acidic polymers. The teichuronic acid of strain C125 eluted at $0 \cdot 29-0.35 \mathrm{M}-\mathrm{NaCl}$ and the teichuronopeptide at $0.40-0.48 \mathrm{M}-\mathrm{NaCl}$ from the column under the conditions also used in this study (Aono, 1985). All the highly acidic polymers which eluted from the DEAEcellulose column at $0.4-0.5 \mathrm{M}-\mathrm{NaCl}$ (Fig. 1) were composed of acidic amino acids and glucuronic acid. Molar 
Table 3. Recoveries of components of macromolecules obtained by hydrazinolysis

The samples $(1 \mathrm{mg})$ were incubated in anhydrous hydrazine at $100^{\circ} \mathrm{C}$ for $3 \mathrm{~h}$. After removal of hydrazine, one-third of each product was fractionated by Sephadex G-15 gel chromatography. Macromolecules eluted at the void volume were assayed for glucuronic acid and amino compounds. The recovery of each compound was calculated taking the content in the original untreated polymer as $100 \%$. Abbreviations: GlcU, glucuronic acid; TUP, teichuronopeptide; AC, total amino compounds.

\begin{tabular}{lccc}
\hline \hline & \multicolumn{2}{c}{ Recovery (\%) } \\
\cline { 2 - 3 } Acidic polymer & AC & GlcU & $M_{\mathrm{r}}^{*}$ \\
\hline A-59 & 8 & 17 & 5000 \\
C-3-2 & 3 & 26 & 4300 \\
C-11 & 8 & 18 & 4700 \\
Y-25-2 & 13 & 28 & 5400 \\
C-125 TUP & 12 & 26 & 4500 \\
Polyglucuronate $\dagger$ & $0.26 \mu \mathrm{mol}$ & $5 \cdot 1 \mu \mathrm{mol}$ & 4800 \\
\hline \hline
\end{tabular}

${ }^{*} M_{\mathrm{r}}$ value of the macromolecule obtained from the teichuronopeptide by hydrazinolysis.

† For polyglucuronate, the results shown are $\mu \mathrm{mol}$ of each constituent per $1 \mathrm{mg}$ of the product purified from the C-125 teichuronopeptide, treated with hydrazinolysis at $100^{\circ} \mathrm{C}$ for $5 \mathrm{~h}$, by gel and DEAE cellulose chromatography (Aono, 1989).

ratios of glucuronic acid to total acidic amino acids were $1: 4 \cdot 7-5 \cdot 4$. These ratios resembled that of $1: 4 \cdot 6$ previously found in the teichuronopeptide of strain C-125 (Table 1). Furthermore, $M_{\mathrm{r}}$ values of these substances were similar to that of $\mathrm{C}-125$ teichuronopeptide. These similarities suggested that the four substances (A-59, C-3-2, C-11 and $\mathrm{Y}-25-2)$ resembled the teichuronopeptide of strain C-125. However, the other polymers (C-3-1 and Y-25-1) that eluted at a lower concentration of $\mathrm{NaCl}$ did not appear to be teichuronic acid on the basis of their chemical composition.

\section{Polypeptide moieties prepared by deglycosylation of teichuronopeptides with TFMS}

The four polymers (A-59, C-3-2, C-11 and Y-25-2) were deglycosylated with TFMS. Macromolecular products were assayed for the residues found in the original polymers (Table 2); the proportions of amino acids were unchanged by this treatment. The molar ratio of aspartic acid:glutamic acid was $1: 2.3$ in the original A-59, and $1: 2 \cdot 1$ in the polypeptide obtained after the TFMS treatment. The ratio of aspartic acid:glutamic acid:glycine was $1: 2 \cdot 1: 0 \cdot 92$ in the original C-3-2 and $1: 2 \cdot 0: 0 \cdot 96$ in the polypeptide. However, the content of glucuronic acid decreased to $0 \cdot 5-2 \cdot 0 \%$ of the acidic amino acids. This suggested that TFMS treatment released almost all the glucuronic acid residue from the original substances. The $M_{\mathrm{r}}$ values of the resulting polypeptides (12000$15000)$ were similar to that (14000) of the polyglutamate prepared from the C-125 teichuronopeptide by the same method (Aono, 1987).

\section{Release of polyglucuronic acid by hydrazinolysis of teichuronopeptide}

The four substances were treated with anhydrous hydrazine. Macromolecular products were analysed (Table 3). In order to enhance recovery of the glucuronic acid moieties, the substances were treated with hydrazine for a short time. Therefore, cleavage of peptide bonds was not complete and the resulting products might have contained a proportion of peptides. These peptides are removable from the polyglutamic acid preparation by DEAE-cellulose chromatography (Aono, 1989). The $M_{\mathrm{r}}$ values $(4300-5400)$ of the products were similar to that (4500) of the product prepared from the C-125 teichuronopeptide and to the size (4800) of the polyglucuronic acid previously prepared from the C-125 teichuronopeptide by hydrazinolysis (Aono, 1989).

\section{Discussion}

Teichuronic acid and teichuronopeptide were effectively extracted with TCA from the cell walls of the four strains belonging to the group 2 alkaliphilic Bacillus spp. The methods used in this study were previously developed for extraction of teichuronic acid and teichuronopeptide from the alkaliphilic Bacillus strain C-125 (Aono, 1985). The results indicated that the methods extracted nonpeptidoglycan components from the cell walls of the group 2 strains. The acidic non-peptidoglycan components extracted with TCA were fractionated by DEAE-cellulose column chromatography. This method also seemed effective in separating acidic components (Fig. 1).

The acidic substances isolated from the organisms were divided into two groups on the basis of the $\mathrm{NaCl}$ concentration required to elute them from the DEAEcellulose column (Fig. 1; Aono, 1985). The higher anionic substances, A-59, C-3-2, C-11, C-125-2 (teichuronopeptide) and $\mathrm{Y}-25-2$, eluted at a higher concentration of $\mathrm{NaCl}$, and were mainly composed of glucuronic acid and acidic amino acids. Molar ratios of glucuronic acid and amino acids were 1:4.6-5.4 (Table 1). $M_{\mathrm{r}}$ values of these substances were estimated as $20000-21000$ by gel chromatography. These results suggested that these substances were similar to one another in their chemical structure.

TFMS has been used to deglycosylate several glycoproteins (Edge et al., 1981). This method was applied to the anionic polymers in order to remove glucuronic acid residues. The TFMS treatment removed most of the glucuronic acid (Table 2). The residues appeared to be 
intact polypeptides. $M_{\mathrm{r}}$ values of these products were 12000-15000. Hydrazinolysis has been used to prepare saccharide chains from glycoproteins (Takasaki et al., 1982). $M_{\mathrm{r}}$ values of the products prepared from these anionic substances by hydrazinolysis ranged between 4300 and 5400 (Table 3).

If one polyglucuronate moiety and one polypeptide moiety were covalently bound in these substances, as in the C-125 teichuronopeptide, the $M_{\mathrm{r}}$ of sodium salts of the polypeptide or polyglucuronate moiety should be $15600-17200$ or $3800-4400$ on the basis of the chemical analyses shown in Table 1 . These values are in close agreement with the experimental value of $12000-15000$ obtained after the TFMS treatment, or 4300-5400 after the hydrazinolysis. $M_{\mathrm{r}}$ values of the polyglutamic acid and polyglucuronic acid prepared from C-125 teichuronopeptide were 14000 and 4800 (Aono, 1987, 1989). Thus, the substances can be concluded to be complex copolymers consisting of polypeptide and polyglucuronate moieties. Their chemical natures are similar to that of the C-125 teichuronopeptide.

The term 'teichuronopeptide' was previously proposed for a complex copolymer isolated from the cell walls of the alkaliphilic Bacillus strain C-125 and composed of poly-L-glutamate and polyglucuronate (Aono, 1989). Substances A-59, C-3-2, C-11 and Y-25-2 are variants of teichuronopeptide. Therefore, the results described here indicate that a type of teichuronopeptide is present in the cell walls of a range of group 2 alkaliphilic Bacillus spp.

This work was partially supported by a grant for the 'Biodesign Research Program' from RIKEN to R. Aono.

\section{References}

AONo, R. (1985). Isolation and partial characterization of structural components of the walls of alkalophilic Bacillus strain C-125. Journal of General Microbiology 131, 105-111.

AONO, R. (1987). Characterization of structural components of cell walls of alkalophilic strain of Bacillus sp. C-125. Biochemical Journal 245, 467-472.
Aono, R. (1989). Characterization of cell wall components of the alkalophilic Bacillus strain C-125: Identification of a polymer composed of polyglutamate and polyglucuronate. Journal of General Microbiology 135, 265-271.

AONo, R. \& HoRIKosHi, K. (1983). Chemical composition of cell walls of alkalophilic strains of Bacillus. Journal of General Microbiology 129, 1083-1087.

Aono, R. \& Uramoto, M. (1986). Presence of fucosamine in teichuronic acid of the alkalophilic Bacillus strain C-125. Biochemical Journal 233, 291-294.

Aono, R., Horikoshi, K. \& Goto, S. (1984). Composition of the peptidoglycan of alkalophilic Bacillus spp. Journal of Bacteriology 157, 688-689.

BeUTLER, H. O. \& Michal, G. (1974). Glutamate, determination with glutamate dehydrogenase, diaphorase and tetrazolium salts. In Methods of Enzymatic Analysis, 2nd edn, vol. 4, pp. 1708-1713. Edited by H. U. Bergmeyer. Weinheim: Verlag Chemie.

DAvidson, E. A. (1966). Analysis of sugars found in mucopolysaccharides. Methods in Enzymology 8, 52-60.

DisCHE, Z. (1947). A specific color reaction for glucuronic acid. Journal of Biological Chemistry 171, 725-730.

Edge, A. S. B., Faltyner, C. R., Hof, L., Reichert, L. E., JR \& WEBER, P. (1981). Deglycosylation of glycoproteins by trifluoromethanesulfonic acid. Analytical Biochemistry 118, 131-137.

GrassL, M. \& SuPP, M. (1985). D-Alanine. In Methods of Enzymatic Analysis, 3rd edn, vol. 8, pp. 336-340. Edited by H. U. Bergmeyer. Weinheim: VCH Verlagsgesellschaft.

Ito, M., Aono, R. \& HoRIKoshI, K. (1993). Identification of quinovosamine in cell wall components from alkaliphilic strain of Bacillus sp. Y-25 by $500 \mathrm{MHz}$ NMR. Carbohydrate Research 242, 173-180.

MöLLERING, H. (1985). L-Aspartate and L-asparagine. In Methods of Enzymatic Analysis, 3rd edn, vol. 8, pp. 350-357. Edited by H. U. Bergmeyer. Weinheim: VCH Verlagsgesellschaft.

SPIES, J. R. (1957). Colorimetric analysis for amino acids. Methods in Enzymology 3, 467-477.

SPIRO, R. G. (1966). Analysis of sugars found in glycoprotein. Methods in Enzymology 8, 3-26.

STEPKA, W. (1957). Identification of amino acids by paper chromatography. Methods in Enzymology 3, 504-528.

TaKasaki, S., Mizouchi, T. \& Kobata, T. (1982). Hydrazinolysis of asparagine-linked sugar chains to produce free oligosaccharides. Methods in Enzymology 83, 263-268.

Trevelyan, W. E., Procter, D. P. \& Harrison, J. S. (1950). Detection of sugars on paper chromatograms. Nature, London 166, 444-445.

WhEAT, R. W. (1966). Analysis of hexosamines in bacterial polysaccharides by chromatographic procedures. Methods in Enzymology 8 , 60-78.

WILliamson, D. H. (1985). L-Alanine: determination with alanine dehydrogenase. In Methods of Enzymatic Analysis, 3rd edn, vol. 8, pp. 341-344. Edited by H. U. Bergmeyer. Weinheim: $\mathrm{VCH}$ Verlagsgesellschaft. 